\title{
The intersectional precarity of platform cycle delivery workers
}

\author{
Cosmin Popan (Department of Sociology, Manchester Metropolitan University) \\ Esther Anaya-Boig (Centre for Environmental Policy, Imperial College London)
}

\section{Abstract}

In less than a decade, with the emergence of food delivery platforms, cycling has gained increased visibility on city roads across the world. For the first time since the advent of the automobile age, the bicycle is re-emerging globally as a dependable tool to earn a living. Food delivery start-ups such as Deliveroo, Uber Eats or Glovo enroll an increasingly precarious population as self-employed contractors to whom they grant little social protection. Having access to a bicycle and knowing how to use it is a very low entrance requirement for these jobs. Cycle food couriers hold a precarious entitlement to the road space, which makes them constantly vulnerable to bodily harm, and is compounded by a broader ontological precarity. The insecurity resulting from being engaged in an unregulated gig economy where job and income instability is amplified by issues of gender, ethnicity and migration status, further adds to road unsafety. In this chapter, we draw on case studies from the UK, Spain and South America to account for how the precarity of cycling is amplified by the political landscape of neoliberalism of the last three decades, which promotes flexible work, and the legislative setting failing to account for cycle couriers as employees.

\section{Introduction: From cycle work to gig work. A brief history}

'As easy as riding a bicycle'. While this is easier said than done, the aphorism remains a powerful claim that cycling is a straightforward skill, which nevertheless produces normative assumptions regarding individual body capabilities. This overoptimistic assertion may also be implying that the bicycle is the most basic vehicle to navigate contemporary urban agglomerations, often 
associated with a desired "sustainability", while often disregarding the overwhelming hostility of automobile-dominated road environments. Similar postulations are also found in contemporary discourses about work, where flexibility and easy access have come to dominate the narrative of the last four decades. Neoliberalism has dramatically reconfigured jobs away from the security of decent full employment, recasting them as malleable while at the same time obscuring the increasingly precarious nature of work. The gig economy, a labour market characterised by independent contacting that takes place via and on digital platforms, represents the most recent attempt to legitimise this flexibility as both normal and desirable.

These strong beliefs that cycling and entrepreneurship are accessible to everyone have come together to explain the popularity that platform food deliveries such as Deliveroo, Uber Eats or Glovo have gained in the recent years in urban environments across the world. One only needs to ride a functional bike, undertake a summary selection process, install an app on their smartphones and they can become 'their own boss'. The bicycle is seen, within this logic, both as a basic requirement and a simple working tool that anyone can ride and afford, which facilitates access to a flexible job. Yet, the reality is anything but different. Contrary to the mainstream appraisal of cycling as empowering and liberating and of gig economy as flexible and entrepreneurial, we observe the opposite situation. Namely, in this chapter we argue that platform work adds an extra level of precarity to the already precarious practice of riding a bicycle in the city. And gender, ethnicity and migrant status further compromises the already fragile living and working conditions of these workers.

To date, cycling for work has not received sufficient research interest. Overwhelmingly, research has focused on cycling for transport, with a particular attention to commuting. Interest in work amongst cycling researchers was tangential: it focused on cycling as means to access work rather than work per se. The notable exception of cycling for work becoming centre stage in research was the case of the literature on cycle messengers from the 2000s (Kidder 2005, Fincham 2006, 2007 , 2008). Authors of cycle messenger literature focused on subcultural identities and lifestyles, while the actual working conditions and labour struggles were not an issue.

Although the actual tasks that platform cycle workers perform might seem similar to that of their predecessors, the advances of neoliberal economy and ICT in the last three decades have given rise to platform work, which is a larger-scale exploitative job opportunity for individuals who do not necessarily identify with their cycling job nor think about it as a lifestyle. The bike messengers 
of 2000s were a romanticised dying breed, as they were essentially carrying physical objects such as legal papers, video tapes and DVDs, which were soon turned into virtual items thanks to advances in technology (Day 2015). On the contrary, platform cycle couriers are either celebrated or feared to represent the future of work as the gig economy is seen as the laboratory of platform capitalism where new techniques of management, control, exploitation and extraction of profit are tested and refined (Cant 2020). During SARS-CoV-2 pandemic, the need to deliver food to the locked-down and quarantined world population and the growth of unemployment, has contributed to an increase of platform cycle couriers; essential but unprotected workers.

Traditional researchers of the gig economy and platform food deliveries do not dwell too much either on reflections about the distinctive nature of riding a bicycle (rather than a scooter, a motorbike or even a car) for work. In this chapter, we contribute to bridging the gap between cycling research and work research by unpacking the implications of gig workers' use of bicycles as a collection of levels of intersectional precarity. In doing so, we aim to further connect the burgeoning domain of cycling studies with some of the most pressing issues impacting contemporary societies: neoliberal rationalities, platform capitalism and the future of work.

Throughout history, the bicycle has constantly found itself at the intersection of work and play. On the one hand, it is intrinsically linked to the rise of capitalism, mass production and consumption. It has effectively mobilised, for most of the previous century, a Western working class commuting to and from factories while at the same time being used on a large scale to transport a great variety of things by a similar great variety of urban tradesmen and service workers. On the other hand, from its very inception in the late 1800s, the bicycle was first a bourgeois pastime and an object of conspicuous consumption before it eventually reached the masses. After half a century of being taken seriously, from the 1950s onwards the bicycle became, at least in the Western world, a leisure object, a child's toy or a sports machine. In the age of mass automobility, the reliance on cycles for everyday commuting and transport diminished drastically.

It is within this shifting context of work and play that the emergent gig economy has appropriated the bicycle. Thanks to platforms such as Deliveroo, Uber Eats, Foodora, Glovo or Rappi, which operate today across all continents, cycling as a job has re-entered the public attention. The concept behind all these food delivery companies, which act as an intermediary between customers and restaurants, is always the same: using an app, customers place and pay for an order, which is then conveyed to the participating restaurant. Riders, who are often cyclists, 
deliver it as quickly as they can, notwithstanding traffic, weather and other conditions. In most cases, they are not considered employees, but freelance workers performing "gigs". In the same way that the bicycle is and is not work, the gig economy is and is not employment.

The role of the bicycle in the flourishing of these platforms is essential; it provides affordable access to a job to pretty much anyone who knows how to use it, as well as easily mobilizing a pool of cheap labour for transnational capital. During their early stages, when entering a new market, platforms are initially covering central urban areas, offer better wages and welcome as many workers as possible. As platforms expand and progress in a specific urban environment, delivery distances may increase and companies start rewarding, through algorithm management, those using motorised vehicles as they can far-reaching destinations faster and deliver more meals in one ride. However, this puts at a disadvantage those who cannot afford a motorised vehicle, creating inequalities amongst workers. Additionally, neoliberal platform companies have been taking advantage of the increase of people in need for jobs during the pandemic, by lowering the wages and dismissing workers unscrupulously.

This chapter adds to a growing body of literature focusing on the precarious working conditions of food couriers in the gig economy (Briziarelli 2018, Lemozy 2019, Veen et al. 2019, Cant 2020, Galière 2020, Gregory 2020, Gregory and Maldonado 2020, Richardson 2020, Woodcock 2020). Most of this literature focuses, on the one hand, on unpacking the exploitative working conditions, enabled by an algorithmic management, which often lacks transparency and accountability. On the other hand, these writers follow the instances where resistance against these working practices are mounted as they try to unpack the extent to which strikes, protests and unionization are possible amongst a workforce which is characterized by a high turnout, a constant geographical mobility and an overall precarity. We aim to expand these debates by focusing on the role of cycling in the gig economy, accounting for the ways in which issues of gender, ethnicity and migration status amplify the job and income insecurities of cycle couriers.

\section{Conceptualising precarity from an intersectional perspective. From the right to a livelihood to the right to the road}


The "gig economy" is driven by the "lean platform economy", developed after the financial crisis of 2007-2008 and heavily relies on venture capital for its rapid growth. It appears as "an outlet for surplus capital in an era of ultra-low interest rates and dire investment opportunities rather than the vanguard destined to revive capitalism" (Srnicek 2016, p. 91). Gig economy describes a labor market characterized by the prevalence of short-term insecure work as opposed to permanent jobs, and has generated heated debates in recent years with the development of a plethora of digital platforms intermediating not only food delivery services, but also transportation (Uber), hosteling (Airbnb), pet, children and elderly care, cleaning, chores and many others. It is estimated that this independent workforce accounts for over 150 million people worldwide and represents a third of the working-age population in the United States and most of Europe (Manyika et al. 2016). In Europe, a high proportion of the population (ranging from $9 \%$ in Germany and the UK to as high as $22 \%$ in Italy) reported having done some crowd work (working "virtually" from their own homes, providing driving or delivering services, or working in somebody else's home) (Huws et al. 2017).

Woodcock and Graham (2020) identify a set of contributing factors to the emergence of platform work world-wide. Amongst them, there are the ubiquity of mass connectivity and cheap technology, but also the changing socio-economic landscape of the last forty years which has led to the state deregulation of work and the weakening of employment protection (2020, pp. 23-38). The desire for flexibility for and from workers is equally important here, with workers wanting to get away from the rigid 9 to 5 jobs, while the companies requiring work on demand and rewarding those who can accommodate their requests.

In Latin America, the emergence of the gig economy must be understood within a context in which historical and structural forms of oppression (colonial and related to the international, sexual and racial labor division) operate in addition to the neoliberal ones. These historical and structural forms of oppression generate the ideal conditions for neoliberal companies to flourish (Hidalgo Cordero and Salazar Daza 2020). Colonial forms of exploitation continue to this day with most of the platform companies operating in Latin America originating and/or being funded by venture capital from the "Global North" (see for example Azevedo and Mascarenhas 2019). Platforms can profit from a weakened labor market hiring cheap human resources with promises of false "entrepreneurship", which intensifies the extractive methods of capitalism from people who are most in need. Additionally, lower internet penetration rates and internet data traffic are partly responsible for slightly fewer South American workers involved in the gig economy (Grigera 
Pre-print of chapter currently under peer-review (submitted March 2021)

2020). The number of gig workers in the Global South is estimated between 30 and 40 million, representing around $1.5 \%$ of the global South workforce, with around 2 million gig workers based in Latin America (Heeks 2019). Labor markets in Latin America are informal, precarious and exploitative.

The appeal of such gig jobs amongst cyclists is due, at least partly, with the flexibility enabled by the bicycle itself through its aforementioned ambiguous relation to work and play. As Bennett (2019, p. 56) observes, 'although it is firmly associated with employment, it also promises escape from work'. This is an important issue to consider if we aim to understand the appeal of cycle deliveries amongst many such workers. Previously, authors have pointed to the conundrum posed by the triad cycling - work - play when highlighting the difficulty to promote cycling as utility transport due to its problematic associations with leisure and pleasure (Aldred 2015). In our case, the playfulness associated with cycling is compounded by gamification strategies deployed by digital platforms to recruit, exploit and keep captive users and workers. Indeed, digital platforms have been shown to use games and gamification to capture "play" in the pursuit of neoliberal rationalization and the managerial optimization of work (Woodcock and Johnson 2017). Spinney and Lin (2019) argue, for example, that dockless bike sharing systems platforms rely on gamelike features to extract user data which is further monetized for profit. Similarly, self-tracking applications such as Strava, often adopted by leisure cyclists, are using gamification and datafication elements for monetary purposes (Sumartojo et al. 2016, Barratt 2017).

With new technologies, some people argue, come new opportunities to which societies will have to adapt in order to benefit from them. According to these visions, it is through "combinations of scaled-up social protection, cognitive re-skilling and flexible labor regulation, [that] a path forward is charted' (Mallett 2020, p. 271). Critics, on the other hand, associate platform work with a generalized precarity. Workers, without many options within a shrinking job market, have to navigate from temporary job to temporary job in a gig economy spinning out of control around ubiquitous smartphones and shiny apps. While this benefits consumers in a permanent quest for convenience, it increases the vulnerability of an increasing plethora of casualised workers (Cant 2020, Woodcock and Graham 2020, Popan 2021).

Having investigated the lived experiences of food cycle couriers in the gig economy in three different contexts, we aim to challenge the prevalent celebratory and emancipatory narrative of the gig economy. In doing so, we follow Anna Tsing's (Tsing 2015, p. 3) astute observation that 
Pre-print of chapter currently under peer-review (submitted March 2021)

'the irony of our times [...] is that everyone depends on capitalism but almost no one has what we used to call a "regular job"'. The anthropologist argues, in consequence, for 'thinking with precarity' as a means to engage with critical lines of inquiry not only into the recent transformations in work and employment, but, more generally, into people's livelihoods. Tsing proposes thus 'an appreciation of current precarity as an earthwide condition [which] allows us to notice this - the situation of our world' (2015, p. 4). Where others might see a much-welcomed work flexibility, we draw attention to the flexible exploitation, or "flexploitation", whereby the precarious are

one day overworked, the following day out of work; one week zero hours, the next thirty on late-night shifts. Not only are their incomes unpredictable, but also their work schedules. One might say the precarious are quantum workers, existing in a superposition of employment states, both temporarily employed and temporarily unemployed. Their social identity is in flux: schizophrenic. A precarious is a worker and a nonworker, a citizen and a non-citizen (Foti 2017, p. 11).

What we are left with is more flexibility for some than for others within an otherwise generalized state of exploitation. Some of these couriers are doing deliveries as a side job and are able to maintain relative control over how much they work, when and even where. Others, relying on platforms for a living, are deprived of any control they have over when and for how long they need to be out on the road with their apps turned on. Platforms, for their part, are keen to emphasize and promote the fact that the majority of gigs are side jobs, when this could not be further from the truth. A notable gap between rhetoric and reality characterizes platform discourses (Fairwork 2020). For example, the language used by platforms to describe their relationship with the workers is carefully picked up to displace their responsibility: talking about "disconnection" instead of officially dismissing a worker; or calling the workers "partners", to avoid legal obligations. Platforms' manipulation of language can create frictions with policies and regulations. These frictions might end up protecting workers or, conversely, benefitting the companies.

We aim to expand the notion of precarity beyond the rather narrow confines of economic insecurity, which results primarily from labor market experiences (Burridge and Gill 2017, p. 26), and starts with the precarity of cyclists as road users. While prevalent uses and understandings of the term "precarious" are linked with anxiety about raw unemployment, there is a more pervasive sense of insecurity and uncertainty suggested by an adjective that has come to describe a deteriorated life condition distributed across regions and social classes. As Ferguson and Li (Ferguson and Li 2018, p. 2) observe, this anxiety is 'not just about paychecks, but equally about issues of identity, gender and family, national membership and so on that [...] were long 
anchored by the social ideal of the "proper job"'. We echo here as well the concept of intersectionality coined by Kimberlé Crenshaw (1989) to account for how cycling, race, class, gender, and other individual characteristics "intersect" with one another and overlap. In doing so, Crenshaw addresses not merely questions of identity and representation, but instead tackles deep structural and systemic questions about discrimination and inequality. We argue that the precarity of cycle food couriers is intersectional, in the sense that issues of gender, race and migration status further impact on what it means to be precarious.

Precarity has also been applied to the type of entitlement that cyclists have as road users (Egan 2019, Egan and Philbin 2021). The three properties that, according to Egan, make the conditions for this precarious entitlement; insecure space, spatial disregard and police neglect, are exacerbated for cycling food couriers. The spaces to which cyclists are entitled and, at times, obliged to use expose them to danger and threats and are perceived as insecure. Frequently, due to poor design, cycling-dedicated or shared spaces make cyclists less visible, more exposed and more vulnerable to road unsafety. Due to the rushed nature of their work, couriers are also forced to navigate these spaces fast while carrying bulky bags that make cycling less comfortable. Furthermore, since these cycle spaces are not designed for the use of couriers, other cyclists may feel unsafe sharing already precarious spaces with faster couriers who often overtake them in inadequate spaces such as narrow cycle lanes. This connects with the aforementioned spatial disregard, which refers both to a disregard for a cyclists' space as well as an inconsideration of cyclists within a particular space. The risk of collision with other road users amongst couriers is undoubtedly amplified by the fact that they spend a good part of their working time on the roads.

Finally, the protection of cyclists is neglected. Egan talks about policing, in the sense of a lack of punishment for those creating insecurity or invading cycling space (e.g. parking on cycle lanes, close passes). In the context of cycle couriers, this lack of protection includes other institutions failing to protect the gig cycle workers who cannot defend themselves against harassment or access adequate accident insurance. Additionally, their physical integrity and health have been further threatened by the inadequate hygienic conditions endured during the Covid-19 pandemic.

This chapter draws on ongoing research investigating working conditions amongst platformbased cycle food couriers undertaken in the UK, Spain and several countries in Latin America. The authors have conducted ethnographic work consisting of participant observation and 15 indepth interviews in Manchester (involving 13 migrant workers and 4 women) and an analysis of 
Pre-print of chapter currently under peer-review (submitted March 2021)

recorded interviews and webinars involving 7 women in unions and a cooperative in Spain and Latin America. These have been supplemented by data produced by riders, unions and similar collective associations gathered from social media platforms, webinars as well as media representations. Broader contextual data was gathered from existing grey literature and online media outlets.

\section{Gender}

The platform economy can provide a source of income for marginalized groups, such as lowskilled or untrained women (Wood et al. 2018). For them, and for women who perceive their main responsibility to be unpaid care work, this could be a gateway into the labor market as it offers them flexibility and task variety (Kohlrausch and Weber 2021). However, the transport and delivery sector has been historically male-dominated, and transport-related platforms are not an exception (Urzi Brancati et al. 2019). For example, in Spain only 13\% of food delivery riders are women (Adigital 2020), in the UK, 6\% of all Deliveroo riders are women (Dupont et al. 2018) and in Argentina they are below 5\% (Madariaga et al. 2019). In cities with a low uptake of cycling like the ones analyzed in this chapter, women are underrepresented in cycling mobility; $33 \%$ in Manchester, UK (Sustrans 2018), 35\% in Barcelona (IERMB 2020) and between 5 and 40\% in Latin American cities (Ríos Flores et al. 2015). Working on a bicycle is a physically demanding activity, as Fincham already noted in his cycle messenger studies, where he found that only one in six cycle messengers in Cardiff, UK, were women and only one in four in London (Fincham 2007, 2008). More generally, women cyclists are perceived to be less competent because their bodies are not considered to be 'proper cycling bodies' (Aldred 2013). As a minority in this working environment, most women develop strategies of self-protection against hostility, sexual harassment and neglect, such as avoiding socialization in the workplace, which in turn has a negative impact in skill development and earnings. Women riders try to find quiet spaces to be on their own or even cover their face to avoid gender assumptions or direct interaction. Women miss opportunities of getting advice from more experienced male colleagues that could help them be more efficient at their jobs. This can lead to making beginner mistakes while using the apps and consequently getting lower app ratings. A second strategy is for women to come together by organizing online gatherings and social media networks. Latin American women riders, for example, participated in a webinar with the meaningful title "Platforms don't take care of us, our female colleagues do" (Las plataformas no me cuidan, me cuidan mis compañeras 2020). 
Pre-print of chapter currently under peer-review (submitted March 2021)

Doing cycle deliveries exposes workers to public spaces for long periods of time. For women, this means constantly experiencing fears and feelings of vulnerability, which makes them feel unsafe, influences their movement and leads to an avoidance of public exposure (McCullough et al. 2019, Lubitow et al. 2020). This suggests that, for some women, engaging in cycle delivery work means forcing themselves into hypermobility and having to negotiate it by, for example, choosing to work in familiar and/or local areas.

In the context of cycle platform deliveries, gender inequalities have health, safety, security and economic impacts on women. For example, access to toilets is key to women's health; these are basic hygiene requirements during menstruation (approximately one fifth of the time for a woman in reproductive age) and pregnancy, and not being able to urinate for long periods of time increases dramatically the risk of urinary infections. It is a basic and frequent need for women to use toilets, which at the same time can expose them to more harassment and abuse, when they need to request restaurants to enter their premises (VICE 2021). The Covid-19 pandemic has further limited access for women to these spaces, which have been partially or totally closed, or made riskier to use due to compromised hygiene conditions.

There are features of platform delivery work that expose women to higher safety and security risks, which often require them to go into buildings or to share their personal contact details (full names, phone numbers) that can be misused to stalk and harass them. Some of these issues have been addressed by companies (e.g. hiding contact details from the riders), but some others are understood as part of the job and protection strategies are a matter of goodwill from clients (e.g. meeting the women riders outside their buildings to collect their food) or depend on women networks (e.g. sharing information about open, clean toilets through social networks). Adding an intersectional approach to Egan's precarious entitlement to the road, women cyclists seem to have a higher exposure to road unsafety. Women report more near misses per hour and per distance unit (mile), with 50\% more close passes per distance unit than men (Aldred and Crosweller 2015). We can expect women riders being more exposed to a higher crash risk while doing the same job.

Not only platform economy reproduces the already existing disadvantages for women in the workplace (Kohlrausch and Weber 2021), but it exacerbates them, especially in vulnerable situations and/or intersectional contexts. Women with caring responsibilities who find themselves in situations of financial insecurity or poverty are profoundly affected by the consequences of 
precarious platform work cases. Unionized women in Latin America call the relationship between these vulnerable women riders and the companies "predatory" and "violent", referring to this oppressive source of power as an abusive male (Las plataformas no me cuidan, me cuidan mis compañeras 2020).

A study analyzing more than a million drivers on the Uber platform in the US found a 7\% earnings gap between men and women drivers (Cook et al. 2018). This was attributed to gender differences in the experience of using the platform, preferences over where and when to work, and driving speed. Similar differences have been observed in our empirical work with cycle delivery riders. Additionally, a study conducted by Team Lease in India observed an 8-10\% difference in monthly salary between male and female delivery company executives (operations and managerial roles) (Kar 2019). That "platformisation" has not managed to directly increase female labor force participation rate in India is indicative of this inequity (Kasliwal 2020).

Women are a minority in delivery platforms, but they have been at the forefront of resistance strategies. Whether it is unionization, peer support groups (e.g. Whatsapp groups), labor movements or cyber activism, women have been involved in all kinds of organized forms of resistance. For example, there are women amongst the co-founders of the organization for the rights of riders "Riders X Derechos" (Riders for rights) in Spain. Women-specific groups have also been created within unions, e.g. IWGB Women's project in the UK or "Ni una repartidora menos" (Not a woman delivery worker less) as part of the Mexican organization "Ni un repartidor menos" (Not a delivery worker less). Alternatives to platform work in the shape of cooperatives like "Mensakas" in Barcelona are also co-founded by women and have a clear feminist perspective, paying women $5 \%$ higher wages to try to compensate for the gender pay-gap in the sector. Accordingly, the color of their visual identity is violet.

\section{Ethnicity and migrant status}

There is a lack of comprehensive or comparative public data on the precise number of ethnic minority and migrant workers in urban gig economies. The few existing statistics show a high volume of such workers undertaking these jobs, providing an 'infrastructural role' for these platforms, 'one that is as vitally important to their business model's viability as the steady influx of investment capital' (van Doorn et al. 2020, p. 2). 
Amongst food couriers, ethnic minority and migrant workers represent the majority in many European countries (Biagi et al. 2018, Eurofund 2018, Don't GIG Up! 2020, Heiland 2020). In our case studies, an overrepresentation of migrants and minority ethnic groups can be observed as well. The majority of cycle couriers in British cities have a migrant background and often tend to rely on these jobs as their main source of income (Cant 2020, Tassinari and Maccarrone 2020, Popan 2021). This reality echoes existing research which shows that migrants and ethnic minorities living in the UK are disproportionately represented in precarious jobs, are exposed to higher risks of exploitation and are often willing to tolerate poorer working conditions (Mcdowell et al. 2009, Anderson 2010, Galván 2012, TUC 2017). The situation is similar in Spain, where $64 \%$ of riders are from Latin America, $28 \%$ from Spain and the rest from the EU and other countries (Adigital 2020). In Argentina, they represent an even bigger fraction of the workers, as $65 \%$ and $84 \%$ of Glovo and Rappi riders are migrants (Hidalgo Cordero and Salazar Daza 2020).

One's ethnicity can negatively impact access to work. Algorithmic bias is one common experience amongst ethnic minority populations (Benjamin 2019) and increasingly visible in the workplace, where automated processes discriminate during hiring and job allocation processes (Vallas and Schor 2020). Amongst food couriers these issues have become apparent in the case of Uber Eats, whose facial identification software was accused of being racist after it proved incapable of recognizing faces and firing ethnic minority workers as a consequence (Kersley 2021).

App renting represents a prevalent phenomenon amongst couriers with an undocumented migrant status, who pay an average of $£ 50$ per week to rent an account in the UK. This practice is also common in France, Spain and Colombia, according to media reports (Alderman 2019, Griffin 2020). Renting occurs happens either because couriers have to wait weeks and months in a row to have their account activated, but also because of their undocumented migrant status. Increasing public scrutiny against undocumented migrant workers has already pushed Uber and Deliveroo to impose stricter surveillance and enforcement techniques. In 2016, the company confirmed that it had assisted the police in a Home Office immigration raid on one of its training centres in London. A police officer was found disguised as a Deliveroo rider in the UK capital, in order to find and arrest undocumented migrant people (Lott-Lavigna 2020) and, more recently, arrests and bike seizures have taken place in south London (Lott-Lavigna 2021). The exploitative nature of this job outsourcing can be compounded by inflammatory anti-immigration headings in the right-wing media, such the one featured in a Daily Mail (UK) article from a few years ago: 
Pre-print of chapter currently under peer-review (submitted March 2021)

'Deliveroo and UberEats riders "are renting their jobs to illegal immigrants in a black market that allows them to work without record checks"' (McManus 2019).

The migrant and transient status of many app-based food-delivery workers often prevents them as well from expressing collective agency (Coe 2013, Tassinari and Maccarrone 2020), either because of the aforementioned undocumented status or because they are simply less aware of their rights (Eurofund 2018). The invisibility of app-renters is perceived as an advantage for those who lack the documentation to access formal jobs, but it silences them and leaves them completely unprotected to any risk. The lethal collision suffered by a Nepalese cyclists while renting the Glovo app in Barcelona is evocative of these risks (Newsdesk / ACN 2019). Within this context, the calls to reclassify cycle couriers as employees rather than self-employed could be interpreted as a barrier for undocumented migrant workers to access these jobs. Exploitative as they are, these jobs nevertheless offer a lifeline to many workers; if these companies are demanded to reclassify their workforce, it is without doubt that this will result in a purge of undocumented migrants from the platform (van Doorn et al. 2020). We argue nevertheless that what these migrant workers ultimately need are systemic policies and procedures that allow them to access a dignified job in the first place.

\section{Concluding reflections}

The public and academic debates of the last few years on the nature of the gig economy have focused on the 'self-employed' without much consideration on who this 'self' is. While examining the phenomenon, the critics of platform work, with few exceptions, did not explore in great depth the implications of the use of cycles for work, and the socio-demographic characteristics of these workers, let alone their historical and cultural backgrounds. This chapter is a first step to address these omissions and show the intersectional layers of complexity to what is already regarded as precarious work, which start by the intrinsic precarity of cycling mobility. We have demonstrated that, amongst cycle food couriers, there is a minority of women as well as a majority of migrants whose work experiences are not only hidden from view under a generic 'self-employed' category, but, most importantly, both these under and overrepresented populations are indicative of additional discrimination and exploitation processes at work in the gig economy. 
The fact that platform companies do not regularly use images of women and ethnic minorities in their promotional materials is indicative of an effort to conceal and even deny their individual work experiences (Vyas 2020). This chapter has begun to unpack these experiences, showing that women riders suffer multiple levels of oppression from the platforms, their workmates, their clients, and the people they are constantly exposed to while on the road. Often, the strategies that women riders develop to address these risks lead to lower levels of workplace integration and earnings. For ethnic minorities and migrants, on the other hand, the platform work experience is aggravated by algorithmic discrimination, while their undocumented status forces them to rent accounts and remain invisible, thus stifling collective resistance against unfair working conditions.

We need situated knowledge in order to tackle these global issues, since both the operation of these companies and the associated worker struggles are global phenomena, albeit with local specificities. We need to draw on research produced in local contexts and process it collaboratively. The perspective from Latin America shows that colonial dynamics are still playing a remarkable role in both how oppression and resistance occur. Colleagues from that region make it clear that they want to recover technology sovereignty and manage it according to their local culture, proposing a conservational approach to production, respectful of life and nature, rather than a neoliberal exploitative one. Challenging neoliberalism and conquering technology could work as a way to resist the history of conquest that Latin America has been subject to (Hidalgo Cordero and Salazar Daza 2020).

Platform delivery work is a fragmented and isolated activity, which makes it difficult for workers to interact and organize. Additionally, companies actively discourage and block any possibilities for communication and networking. Despite this, and the extreme vulnerabilities faced by gig workers, there is room for creative resistance strategies that go beyond traditional forms of collective organization and happen in the streets or on social media. Sororities such as those formed by unionized female riders in Latin America aim to counterbalance the negative effects of these multiple levels of oppression. Similarly, newer grassroots trade unions such as the Independent Workers Union of Great Britain and United Voices of the World have come into existence and have started to represent migrant voices in precarious employment, including the gig economy, even at global levels. 


\section{Bibliography}

Adigital, 2020. Importancia económica de las plataformas digitales de delivery y perfil de los repartidores. Spain: Adigital.

Alderman, L., 2019. Food-Delivery Couriers Exploit Desperate Migrants in France. The New York Times, 16 Jun.

Aldred, R., 2013. Incompetent or Too Competent? Negotiating Everyday Cycling Identities in a Motor Dominated Society. Mobilities, 8 (2), 252-271.

Aldred, R., 2015. A Matter of Utility? Rationalising Cycling, Cycling Rationalities. Mobilities, 10 (5), 686-705.

Aldred, R. and Crosweller, S., 2015. Investigating the rates and impacts of near misses and related incidents among UK cyclists. Journal of Transport \& Health, 2 (3), 379-393.

Anderson, B., 2010. Migration, immigration controls and the fashioning of precarious workers. Work, Employment and Society, 24 (2), 300-317.

Azevedo, M.A. and Mascarenhas, N., 2019. Colombian On-Demand Delivery Unicorn Rappi Raises \$1B From SoftBank [online]. Crunchbase News. Available from: https://news.crunchbase.com/news/colombian-unicorn-rappi-reportedly-raising-1b-fromsoftbank/ [Accessed 4 Mar 2021].

Barratt, P., 2017. Healthy competition: A qualitative study investigating persuasive technologies and the gamification of cycling. Health \& Place, 46, 328-336.

Benjamin, R., 2019. Race After Technology: Abolitionist Tools for the New Jim Code. Cambridge: Polity.

Bennett, B., 2019. Cycling and Cinema. London: Goldsmiths Press.

Biagi, F., Grubanov-Boskovic, S., Natale, F., and Sebastian, L.R., 2018. Migrant workers and the digital transformation in the EU. Luxembourg: Publications Office of the European Union.

Briziarelli, M., 2018. Spatial politics in the digital realm: the logistics/precarity dialectics and Deliveroo's tertiary space struggles. Cultural Studies, 0 (0), 1-18.

Burridge, A. and Gill, N., 2017. Conveyor-Belt Justice: Precarity, Access to Justice, and Uneven Geographies of Legal Aid in UK Asylum Appeals. Antipode, 49 (1), 23-42.

Cant, C., 2020. Riding for Deliveroo: Resistance in the New Economy. Cambridge: Polity.

Coe, N.M., 2013. Geographies of production III: Making space for labour. Progress in Human Geography, 37 (2), 271-284.

Cook, C., Diamond, R., Hall, J., List, J.A., and Oyer, P., 2018. The Gender Earnings Gap in the Gig Economy: Evidence from over a Million Rideshare Drivers. Cambridge, MA: National Bureau of Economic Research, No. Working paper 24732.

Crenshaw, K., 1989. Demarginalizing the Intersection of Race and Sex: A Black Feminist Critique of Antidiscrimination Doctrine, Feminist Theory and Antiracist Politics. The University of Chicago Legal Forum, 1989, 139-167.

Day, J., 2015. Cyclogeography: Journeys of a London Bicycle Courier. Honiton, Devon: Notting Hill Editions.

Don't GIG Up!, 2020. Don't Gig Up. Final Report.

van Doorn, N., Ferrari, F., and Graham, M., 2020. Migration and Migrant Labour in the Gig Economy: An Intervention. Social Science Research Network.

Dupont, J., Hughes, S., Wolf, R., and Wride, S., 2018. Freedom and Flexibility. The relationship Deliveroo riders have with the labour market. London: Public First.

Egan, R., 2019. Precarious entitlement to public space and utility cycling in Dublin: a grounded theory study. PhD thesis. Dublin City University, Dublin. 
Pre-print of chapter currently under peer-review (submitted March 2021)

Egan, R. and Philbin, M., 2021. Precarious entitlement to public space \& utility cycling in Dublin. Mobilities, 0 (0), 1-15.

Eurofund, 2018. Employment and working conditions of selected types of platform work. Luxembourg: Publications Office of the European Union.

Fairwork, 2020. The Gig Economy and Covid-19: Fairwork Report on Platform Policies. Oxford, United Kingdom.

Ferguson, J. and Li, T.M., 2018. Beyond the "Proper Job:" Political-economic Analysis after the Century of Labouring Man.

Fincham, B., 2006. Bicycle messengers and the road to freedom. The Sociological Review, 54 (s1), 208-222.

Fincham, B., 2007. Bicycle Messengers: Image, Identity and Community. In: P. Rosen, D. Horton, and P. Cox, eds. Cycling and Society. Aldershot: Ashgate, 179-195.

Fincham, B., 2008. Balance is Everything: Bicycle Messengers, Work and Leisure. Sociology, $42(4), 618-634$.

Foti, A., 2017. General Theory of the Precariat: Great Recession, Revolution, Reaction. Amsterdam: Institute of Network Cultures.

Galière, S., 2020. When food-delivery platform workers consent to algorithmic management: a Foucauldian perspective. New Technology, Work and Employment, n/a (0), 1-14.

Galván, J.L.Á., 2012. Good or bad jobs?: Contrasting workers' expectations and jobs in Mexican call centres. In: C. Warhurst, F. Carré, P. Findlay, and C. Tilly, eds. Are Bad Jobs Inevitable? Trends, Determinants and Responses to Job Quality in the Twenty-First Century. Basingstoke: Palgrave MacMillan, 160-175.

Gregory, K., 2020. 'My Life Is More Valuable Than This': Understanding Risk among OnDemand Food Couriers in Edinburgh. Work, Employment and Society, 00, 1-16.

Gregory, K. and Maldonado, M.P., 2020. Delivering Edinburgh: uncovering the digital geography of platform labour in the city. Information, Communication \& Society, 23 (8), 1187-1202.

Griffin, O., 2020. Unwanted delivery: Rappi spawns black market in worker accounts. Reuters, 24 Sep.

Grigera, J., 2020. Futures of work in Latin America: between technological innovation and crisis.

Heeks, R., 2019. How Many Platform Workers Are There in the Global South? ICTs for Development.

Heiland, H., 2020. Workers' Voice in platform labour: An Overview. Düsseldorf: Hans-BöcklerStiftung, Wirtschafts- und Sozialwissenschaftliches Institut.

Hidalgo Cordero, K. and Salazar Daza, C., eds., 2020. Precarización Laboral en Platformas Digitales. Una Lectura desde América Latina. Quito, Ecuador: Friedrich-Ebert-Stiftung Ecuador FES-ILDIS.

Huws, U., Spencer, N., Syrdal, D., and Holts, K., 2017. Work in the European Gig Economy. Research Results from the UK, Sweden, Germany, Austria, the Netherlands, Switzerland and Italy. Brussels: FEPS, UNI Europa, University of Hertfordshire.

IERMB, 2020. Enquesta de Mobilitat en Dia Feiner 2019 (EMEF). La mobilitat a Barcelona. Barcelona: ATM, AMB, Ajuntament de Barcelona, AMTU, IDESCAT.

Kar, S., 2019. Women bag frontline roles in gig economy, but lag behind in wages - The Economic Times. The Economic Times, 30 Jul.

Kasliwal, R., 2020. Gender and the Gig Economy: A Qualitative Study of Gig Platforms for Women Workers. Observer Research Foundation, ORF Issue Brief No. 359.

Kersley, A., 2021. Couriers say Uber's 'racist' facial identification tech got them fired. Wired UK.

Kidder, J.L., 2005. Style and Action: A Decoding of Bike Messenger Symbols. Journal of Contemporary Ethnography, 34 (3), 344-367.

Kohlrausch, B. and Weber, L., 2021. Gender Relations at the Digitalised Workplace: The Interrelation Between Digitalisation, Gender, and Work. Gender a výzkum / Gender and Research, 21 (2), 13-31. 
Pre-print of chapter currently under peer-review (submitted March 2021)

Las plataformas no me cuidan, me cuidan mis compañeras, 2020.

Lemozy, F., 2019. La tête dans le guidon. Être coursier à vélo avec Deliveroo. La nouvelle revue du travail, (14).

Lott-Lavigna, R., 2020. 'Police Officer' Spotted Disguised as Deliveroo Rider in London [online]. Vice. Available from: https://www.vice.com/en_uk/article/pky9m8/police-officer-deliveroouniform-london [Accessed 15 Sep 2020].

Lott-Lavigna, R., 2021. UK Cops Boast of Detaining Key Workers for Immigration Checks [online]. Vice. Available from: https://www.vice.com/en/article/m7evzy/uk-cops-boast-ofdetaining-key-workers-for-immigration-checks [Accessed 19 May 2021].

Lubitow, A., Abelson, M.J., and Carpenter, E., 2020. Transforming mobility justice: Gendered harassment and violence on transit. Journal of Transport Geography, 82, 102601.

Madariaga, J., Buenadicha, C., Molina, E., and Ernst, C., 2019. Economía de plataformas y empleo: ¿Cómo es trabajar para una app en Argentina? Inter-American Development Bank.

Mallett, R.W., 2020. Seeing the 'Changing Nature of Work' through a Precarity Lens. Global Labour Journal, 11 (3).

Manyika, J., Lund, S., Bughin, J., Robinson, K., Mischke, J., and Mahajan, D., 2016. Independent work: Choice, necessity, and the gig economy. McKinsey Global Institute.

McCullough, S.R., Lugo, A., and Stokkum, R. van, 2019. Making Bicycling Equitable: Lessons from Sociocultural Research.

Mcdowell, L., Batnitzky, A., and Dyer, S., 2009. Precarious Work and Economic Migration: Emerging Immigrant Divisions of Labour in Greater London's Service Sector. International Journal of Urban and Regional Research, 33 (1), 3-25.

McManus, L., 2019. Deliveroo and Uber Eats riders 'renting jobs to illegal immigrants' [online]. Mail Online. Available from: https://www.dailymail.co.uk/news/article-6562151/DeliverooUber-Eats-riders-renting-jobs-illegal-immigrants.html [Accessed 26 Feb 2021].

Newsdesk / ACN, 2019. Trade union demands investigation into Glovo. Spain in English, 1 Jun.

Popan, C., 2021. Algorithmic Governance in the Gig Economy: Entrepreneurialism and Solidarity Amongst Food Delivery Workers. In: D. Zuev, K. Psarikidou, and C. Popan, eds. Cycling Societies: Innovations, Inequalities and Governance. Oxford, UK: Routledge, 239-257.

Richardson, L., 2020. Platforms, Markets, and Contingent Calculation: The Flexible Arrangement of the Delivered Meal. Antipode, 52 (3), 619-636.

Ríos Flores, R.A., Taddia, A.P., Pardo, C., and Lleras, N., 2015. Ciclo-inclusión en América Latina y el Caribe: Guía para impulsar el uso de la bicicleta. Tomado de: https://publications. iadb. org/handle/11319/6808.

Spinney, J. and Lin, W.-I., 2019. (Mobility) Fixing the Taiwanese bicycle industry: the production and economisation of cycling culture in pursuit of accumulation. Mobilities, 0 (0), 1-21.

Srnicek, N., 2016. Platform Capitalism. Cambridge, UK; Malden, MA: Polity Press.

Sumartojo, S., Pink, S., Lupton, D., and Heyes LaBond, C., 2016. The affective intensities of datafied space. Emotion, Space and Society, 21, 33-40.

Sustrans, 2018. Women: reducing the gender gap. UK: Sustrans.

Tassinari, A. and Maccarrone, V., 2020. Riders on the Storm: Workplace Solidarity among Gig Economy Couriers in Italy and the UK. Work, Employment and Society, 34 (1), 35-54.

Tsing, A., 2015. The Mushroom at the End of the World. On the Possibility of Life in Capitalist Ruins. Oxford: Princeton University Press.

TUC, 2017. Insecure work and Ethnicity.

Urzi Brancati, C., Pesole, A., and Fernández Macías, E., 2019. Digital Labour Platforms in Europe: numbers, profiles, and employment status of platform workers. LU: Publications Office. 
Vallas, S. and Schor, J.B., 2020. What Do Platforms Do? Understanding the Gig Economy. Annual Review of Sociology, 46 (1), null.

Veen, A., Barratt, T., and Goods, C., 2019. Platform-capital's 'App-etite' for control: A labour process analysis of food-delivery work in Australia. Work, Employment and Society, 34 (3), 388-406.

VICE, 2021. The Dark Side of Being a Food Delivery Person. VICE.

Vyas, N., 2020. 'Gender inequality- now available on digital platform': an interplay between gender equality and the gig economy in the European Union. European Labour Law Journal, 2031952520953856.

Wood, A.J., Graham, M., Lehdonvirta, V., and Hjorth, I., 2018. Good Gig, Bad Gig: Autonomy and Algorithmic Control in the Global Gig Economy. Work, Employment and Society, 33 (1), 56-75.

Woodcock, J., 2020. The algorithmic panopticon at Deliveroo: Measurement, precarity, and the illusion of control. Ephemera, 20 (3), 67-95.

Woodcock, J. and Graham, M., 2020. The Gig Economy: A Critical Introduction. 1 edition. Cambridge ; Medford, MA: Polity.

Woodcock, J. and Johnson, M.R., 2017. Gamification: What it is, and how to fight it. The Sociological Review, 0 (0), The Sociological Review. 